\title{
Alloxan-induced diabetes delays repair in a rat model of closed tibial fracture
}

\author{
S.F. Diniz¹, F.P.L.G. Amorim¹, F.F. Cavalcante-Neto¹, A.L. Bocca², A.C. Batista ${ }^{3}$, \\ G.E.P.M. Simm ${ }^{4}$ and T.A. Silva ${ }^{4}$
}

${ }^{1}$ Departamento de Patologia, Faculdade de Medicina, ${ }^{2}$ Departamento de Biologia Celular, Instituto de Biologia, Universidade de Brasília, Brasília, DF, Brasil

${ }^{3}$ Departamento de Estomatologia (Patologia Oral), Faculdade de Odontologia, Universidade Federal de Goiás, Goiânia, GO, Brasil

${ }^{4}$ Departamento de Clínica, Patologia e Cirurgia Odontológicas, Faculdade de Odontologia, Universidade

Federal de Minas Gerais, Belo Horizonte, MG, Brasil

Correspondence to: T.A. Silva, Departamento de Clínica, Patologia e Cirurgia Odontológicas, Faculdade de Odontologia, Universidade Federal de Minas Gerais, Av. Antônio Carlos, 6627, 31270-901 Belo

Horizonte, MG, Brasil

Fax: +55-31-3499-2430. E-mail: tarcilia@odonto.ufmg.br

\begin{abstract}
A closed fracture was performed on the left tibia of 3-month-old Wistar rats weighing 250 to $350 \mathrm{~g}$ that were either healthy ( $\mathrm{N}=$ $24)$ or made diabetic with alloxan $(\mathrm{N}=24)$ to investigate the effect of alloxan-induced diabetes on the course of bone fracture healing. Histomorphometric analysis of the fracture site was performed at 7, 14, 25, and 35 days. After 7 days, diabetic rats had significantly less cartilage $(P=0.045)$ and greater fibrous connective $(P=0.006)$ tissue formation at the fracture site compared to controls. In contrast, marked callus formation was seen in diabetic rats with significant osteogenesis $(P=0.011, P=0.010$, $P=0.010$, respectively, for 14,25 , and 35 days) and chondrogenesis $(P=0.028, P=0.033, P=0.019)$ compared to controls. Radiographic analysis revealed a displaced fracture with poor bone fragment alignment and delayed consolidation at these times in the diabetic group. The levels of alkaline phosphatase were significantly higher in diabetic rats at 25 days $(P=0.009)$. These results suggest that the initial excessive formation of fibrous connective tissue associated with delay in chondrogenesis and osteogenesis may not provide suitable stability of the fractured site, contributing to the inappropriate alignment of fragments and an increase in the volume of callus in later stages of repair. The resulting displaced fracture in diabetic rats requires long periods for remodeling and complete bone consolidation.
\end{abstract}

Key words: Alloxan; Diabetes; Fracture repair; Closed fracture

Received May 24, 2007. Accepted April 14, 2008

\section{Introduction}

Diabetes mellitus is a metabolic disorder characterized by disturbances in the metabolism of carbohydrates, proteins and lipids as a result of absolute or moderate insulin deficiency (1). Diabetes affects some 16 million Americans, approximately $2-4 \%$ of the population, and is responsible for over 40,000 deaths and 20,000 amputations annually in the United States. In Brazil, the prevalence of diabetes is similar, with the estimated number of affected adults expected to rise to 11.6 million by the year 2025 . It is notable that $40 \%$ of carriers are unaware that they have the disease (2-4).

Diabetes has been associated with an extensive list of complications involving various tissues in the body, including bone (1). Previous studies have shown a relationship between diabetes and delayed fracture healing and bone defects in human and animal models (5-13). Fracture healing is a complex process, involving a cascade of synthesis and activation of matrix- and cell-derived molecules that coordinate the restoration of mechanical stability at the fracture site. Immediately after fracture, a hematoma forms to fill the fracture gap and the inflammatory response is activated in the area surrounding the bone 
injury (14-17). The initial hematoma after injury is important as a source of molecules that stimulate inflammation and proliferation. Afterwards, the hematoma organizes itself contributing to remodeling of the fractured ends of the bone. This fusiform and predominantly uncalcified tissue, called soft tissue callus or procallus, provides some anchorage between the ends of the fractured bone, but offers no structural rigidity for weight bearing. Subsequently, activated mesenchymal cells in the soft tissue and bone surrounding the fracture line also differentiate into chondroblasts that produce the fibrocartilage and hyaline cartilage. The newly formed cartilage undergoes endochondral ossification. Furthermore, the activated osteoprogenitor cells deposit subperiosteal trabeculae of woven bone. Finally, the process of remodeling, in which relatively disorganized woven bone is gradually replaced by more mature lamellar bone, occurs over a period of weeks. In this manner, the fratured ends are bridged by a bony callus $(16,17)$.

Several mechanisms have been proposed to explain the greater incidence of delayed healing and non-union of fractures in diabetes. These include reduction in blood supply and angiogenesis (1), a more severe inflammatory response $(18,19)$, a decrease in collagen synthesis $(6,20$, $21)$, a disturbance in the mineralization process $(9,11,12)$, and an imbalance between bone resorption by osteoclasts and bone deposition by osteoblasts (22-24). Another contributing factor may be the advanced glycation end products, present in high levels in diabetic individuals, that amplify inflammatory events (25) and delay wound healing (26). In general, these mechanisms would be expected to affect all stages of fracture healing.

Fracture healing and bone defects have been extensively studied in a variety of diabetes models including spontaneously diabetic BB/O(ttawa)K(arlsburg) rats (912), BB Wistar rats (8) and streptozotocin-induced diabetic rats $(6,7)$. Alloxan exerts direct cytotoxic action on the pancreatic islets, thereby eliminating the production of insulin and causing severe hyperglycemia in the animal. This situation is somewhat analogous to type 1 diabetes in humans $(27,28)$.

The purpose of the present study was to evaluate the effects of alloxan-induced diabetes on the course of fracture healing. We observed an initial excessive formation of fibrous connective tissue associated with a delay in chondrogenesis and osteogenesis.

\section{Material and Methods}

\section{Animals}

A total of 48 skeletally mature, male, 3-month-old Wistar rats (Rattus norvegicus albinus) weighing 250 to $350 \mathrm{~g}$ were used in this study. Rats were randomly assigned to the diabetic or control group. The Animal Care Committee at the University of Brasília approved all procedures performed.

\section{Alloxan-induced diabetes model}

Diabetes was induced by a single intraperitoneal injection of $150 \mathrm{mg} / \mathrm{kg}$ monohydrated alloxan (Sigma, St. Louis, MO, USA) dissolved in sterile $0.9 \%$ saline. Rats were made to fast prior to alloxan administration. After $12 \mathrm{~h}$, a $10 \%$ glucose solution was offered to the animals to prevent hypoglycemia $(27,28)$. After $72 \mathrm{~h}$, blood samples were collected from the tail vein of the animals for evaluation of plasma glucose levels by the glucose-oxidase enzymatic method using Accu-Chek Advantage (Boehringer, Germany). Animals presenting glucose levels above 200 mg/ $\mathrm{dL}$ were included in the diabetic group $(\mathrm{N}=24)$. The animals presenting reversion of the signs of diabetes, i.e., those presenting glucose levels below $200 \mathrm{mg} / \mathrm{dL}$, were excluded from this study. The examinations were repeated every 7 days to confirm maintenance of the glucose levels. The pancreas was obtained from control and diabetic animals for routine histopathological analysis.

\section{Tibia fracture and specimen preparation}

Using general anesthesia with ketamine $(200 \mathrm{mg} / \mathrm{kg})$ and xylazine $(10 \mathrm{mg} / \mathrm{kg})$, closed fracture was inflicted manually on the middle of the left tibia. The traces of all fractures were similar, with no exposure to the outer environment, as previously described (29). Given the need to obtain fractures in as similar a manner as possible to enable comparison during the trial, all fractures were performed by the same investigator.

The control $(\mathrm{N}=24)$ and diabetic $(\mathrm{N}=24)$ groups were sacrificed at $7,14,25$ and 35 days $(N=6$ at each time following the fracture). For the histological studies, the entire tibia was used after disarticulating it from the knee and ankle. The specimens were fixed in $10 \%$ buffered formaldehyde for $24 \mathrm{~h}$, decalcified in $1 \%$ nitric acid for $24 \mathrm{~h}$ and embedded in paraffin blocks. Approximately thirty 5$\mu \mathrm{m}$ thick sections were obtained from each paraffin block. Approximately 6 hematoxylin and eosin-stained sections containing the area of the fracture callus were selected from each paraffin block for use in subsequent analyses. Microscopic analysis was performed by two pathologists who were blind to the identity of the specimens.

\section{Histomorphometry}

Three representative slides of six animals at each time point were selected for histomorphometric analysis. Meas- 
urements of the areas of fibrous connective, cartilaginous and bone tissues at the fracture callus were averaged in six fields selected by systematic sampling in a stepwise manner, moving the microscope stage from left to right and then down and across in order to avoid measuring the same area twice. The area of each tissue at $25 \mathrm{X}$ magnification was obtained by drawing boundaries using the software Image $\mathrm{J}$ (National Institutes of Health, USA).

\section{Radiographic analysis}

Radiographs were used to analyze the gross appearance of the fracture callus and bone remodeling. Radiographic analysis was performed by taking lateral radiographs (Spectro 70X Electronic, Dabi Atlante, Ribeirão Preto, SP, Brazil) at a setting of $0.6 \mathrm{kv}$ for $15 \mathrm{~s}$ of both the experimental $(N=6)$ and control $(N=5)$ legs at days 14,21 , and 30 after fracture. The radiographs were developed on Kodak 10-41 occlusal size 4 film (Eastman Kodak Co., Rochester, NY, USA). The bridging of the fracture callus was described by two independent observers who were blinded to the identity of the specimens.

\section{Alkaline phosphatase activity}

Blood samples ( $1 \mathrm{~mL}$ each) were taken by intracardiac puncture before sacrifice on days 7, 14, 21, and 30, and stored at $-20^{\circ} \mathrm{C}$ until analysis. Serum concentration of alkaline phosphatase (ALP) was measured with a commercially available kit (Labtest Diagnóstica, Lagoa Santa, MG, Brazil). ALP was measured colorimetrically and assayed by the hydrolysis of thymolphthalein monophosphate in alkaline buffer solution at $37^{\circ} \mathrm{C}$. Absorbance of thymolphthalein was determined at $590 \mathrm{~nm}$. Results are reported as units ( $\mu \mathrm{mol}$ thymolphthalein released/min) per $\mathrm{mL}$.

\section{Statistical analysis}

Data are reported as mean \pm standard deviation (SD).
Comparative analysis was performed using the non-parametric Mann-Whitney test. All analyses were made using the SPSS 12.0 statistical software package (SPSS Inc., Chicago, IL, USA).

\section{Results}

\section{Blood-glucose levels}

Blood-glucose levels were significantly $(P<0.01)$ higher (3-5 times) in diabetic rats than controls at all times before and after fracture. An increase of glucose levels (1-2 times) was observed after fracture in both groups. Consistent with this, pancreatic islets exposed to alloxan demonstrated disorganization, reduction of size and loss of architecture in comparison with controls (data not shown). Treatment with alloxan did not significantly affect body weight throughout the experimental period (data not shown).

\section{Histological and histomorphometric findings}

On day 7, diabetic rats had significantly less bone (15.2 and $7.3 \%$ of total callus area for controls and diabetics, respectively; $P=0.068)$ and cartilage $(24.7$ and $12.2 \%$ of total callus area; $P=0.045)$, and demonstrated greater fibrous connective tissue formation (31.5 and $55.4 \%$ of total callus area; $P=0.006$ ) at the fracture site (Figure 1).

In contrast, marked callus formation was seen after 14 and 25 days, with greater bone formation (26.5 and $52.1 \%$ of total callus area, for controls and diabetics, respectively, at 14 days, $P=0.011 ; 31.9$ and $75.2 \%$ of total callus area for controls and diabetics, respectively, at 25 days, $P=$ $0.010)$. Moreover, significantly more cartilage was seen in the diabetic group ( 30.2 and $51.1 \%$ of total callus area for controls and diabetics at 14 days, $\mathrm{P}=0.028 ; 9.1$ and $20.9 \%$ of total callus area for controls and diabetics at 25 days, $\mathrm{P}=0.033$ ). On the other hand, an abrupt decline in fibrous tissue formation was observed in diabetic rats,
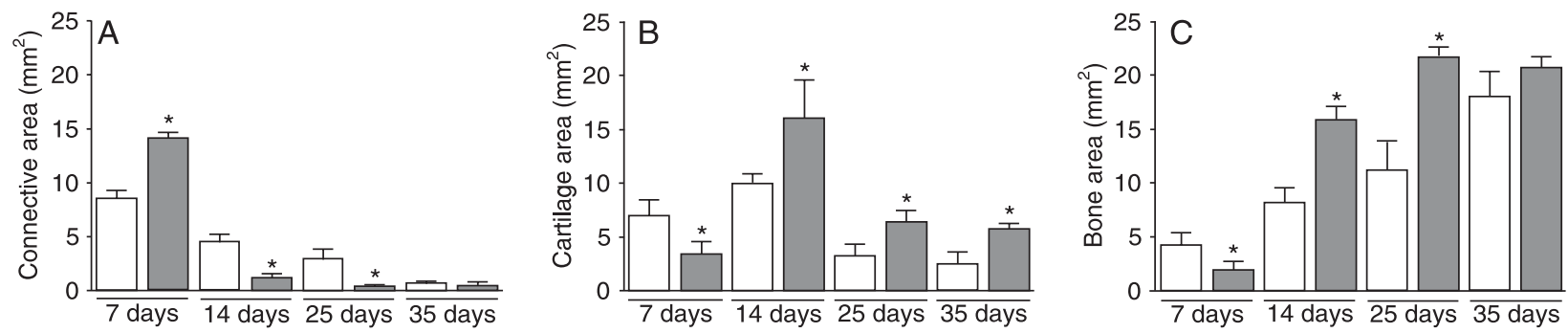

Figure 1. Quantitative analysis of fibrous connective tissue (A), cartilage (B) and bone (C) formation at the sites of tibia fracture. Tissue formation $7,14,25$, and 35 days after tibia fracture was measured with image analysis-assisted histomorphometry of hematoxylin and eosin-stained sections as described in Material and Methods. Normal controls (open bars) and alloxan-induced diabetic rats (closed bars). Results are reported as mean $\pm \mathrm{SD}$ for six specimens per $\mathrm{mm}^{2}$. ${ }^{*} \mathrm{P}<0.05$ compared to control (MannWhitney test). 
resulting in a smaller area of fibrous connective tissue in this group (13.8 and $3.3 \%$, and 8.6 and $1.1 \%$ of total callus area for controls and diabetics, respectively, at $14, \mathrm{P}=$ 0.011 , and 25 days, $P=0.019)$. At 21 days, the fracture callus was formed mostly by the bone and cartilage in both groups (Figure 1).

After 35 days, diabetic rats still demonstrated extensive cartilage ( 7.2 and $20.6 \%$ of total callus area for control and diabetics, respectively; $P=0.019$ ) and bone formation (54.6 and $77.4 \%$ of total callus area; $P=0.010$ ), but no difference in the fibrous connective tissue area (2.1 and $1.96 \%$ of total callus area; $P=0.286$ ) was observed in relation to controls (Figure 1 ).

Despite the differences in the callus area of fibrous connective tissue, cartilage and bone at each time, the callus configuration was observed to be similar in both groups with identical peaks of formation for each tissue occurring at 7 days for fibrous connective tissue, 14 days for cartilage and 35 days for bone (Figure 1).

At day 7, new woven bone, indicative of intramembranous ossification, was observed in controls at the inferior margins of the fracture callus (Figure $2 \mathrm{~A}$ ), whereas mostly fibrous connective tissue was noted at the fracture site of the diabetic rats (Figure 2B). Interestingly, at day 21, the trabecular bone of controls exhibited a greater number of medullary spaces (Figure $2 \mathrm{C}$ ) than the diabetic group (Figure 2D).

Although alignment of the bone extremities slightly improved when the closed tibia fractures were immobilized in a plaster of Paris cast, similar histologic and histomorphometric results were obtained when comparing each group with or without fracture immobilization (data not shown).

\section{Radiographic findings}

To characterize the bridging of the fracture callus, $X$ rays were performed at days 14,25 , and 35 . On day 14 , the griding size of the fracture callus was larger in control rats (Figure 3A) compared to diabetic rats (Figure 3B). On day 25 , the progressive consolidation of the fracture gap in the diabetic group was not clearly recognizable when compared with the controls. A bone bridge was observed between proximal and distal bone fragments adjacent to the fracture in the control group (Figure 3C). In contrast, a displaced fracture with poor alignment of bone fragments was observed in the diabetic rats (Figure 3D). On day 35, radiographs showed more rapid reconstitution of cortices in controls (Figure 3E,F).

Grossly, no leg length discrepancy or limitation of movement was noted between diabetics and controls at days 14,25 , or 35 after fracture.
Figure 2. Hematoxylin and eosin staining of fracture callus for controls [(A) day 7, (C) day 21], and alloxaninduced diabetic rats $[(B)$ day $7,(D)$ day 21]. $\mathrm{Ft}=$ end of fractured tibia; $\mathrm{Tb}=$ trabecular bone; $\mathrm{Fc}=$ fibrous connective tissue; $\mathrm{Ca}=$ cartilaginous tissue. Original magnification $=25 \mathrm{X}$. Bar $=10 \mu \mathrm{m}$.
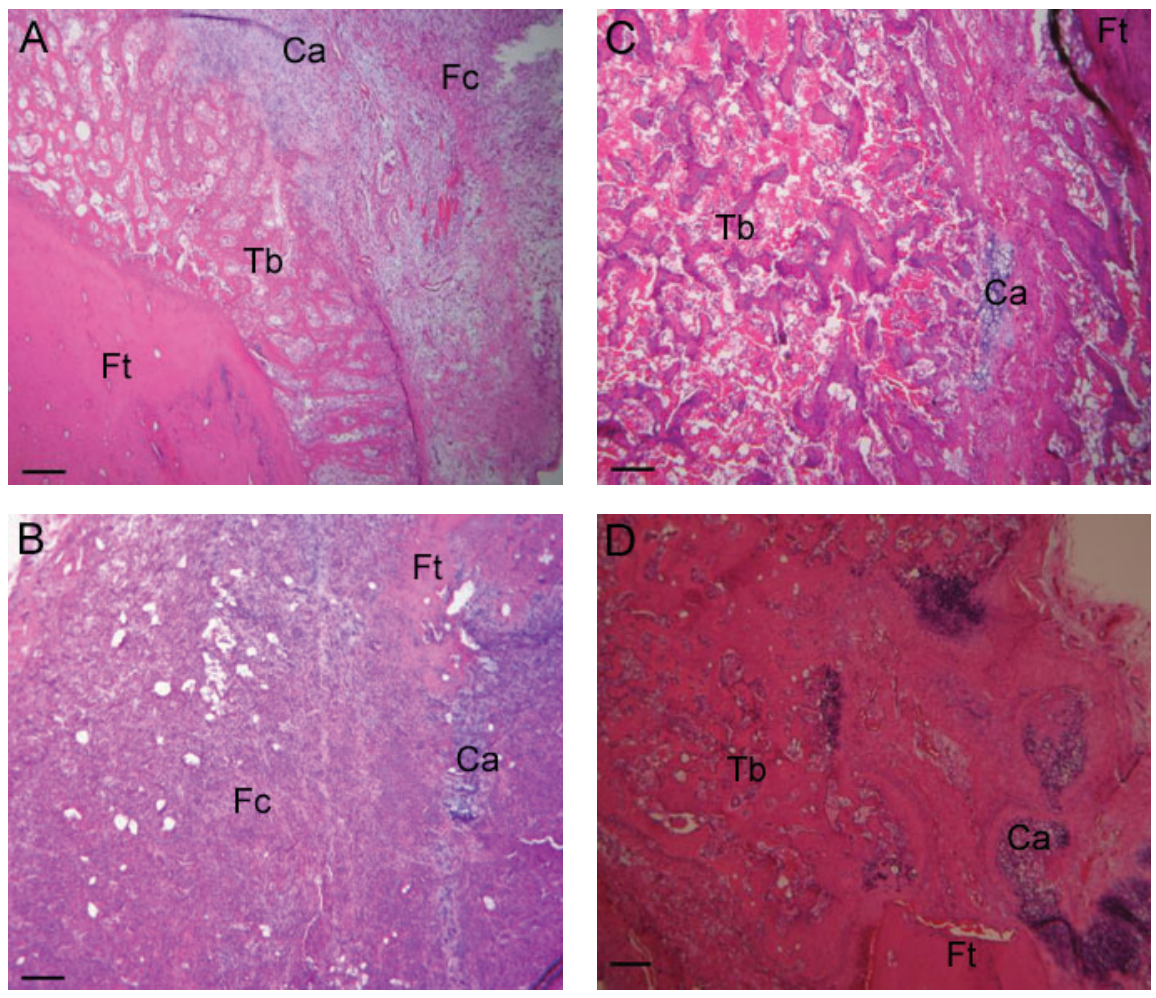
Figure 3. Lateral radiographs of fractured tibias for controls $(A$, day $14, C$, day $25, E$, day 35$)$, and diabetics ( $B$, day $14, D$, day 28 , E, day 35$)$.

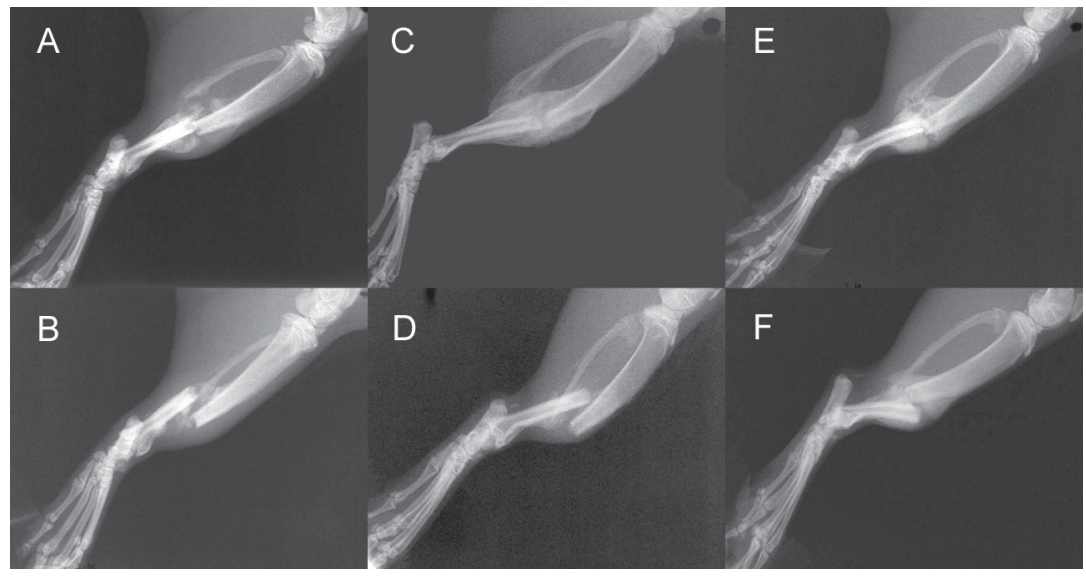

Alkaline phosphatase activity

Consistent with increased osteogenesis in diabetic rats from 14 days, the levels of ALP were significantly higher in this group at $14(P=0.06)$ and $25(P=0.009)$ days (Figure 4). Moreover, the serum ALP levels of diabetic rats correlated positively with bone tissue formation (Pearson correlation, $\mathrm{R}^{2}=0.526 ; \mathrm{P}<0.01$ ). The ALP levels of diabetic rats that did not undergo tibia fracture were similar to those of the control group (data not shown).

\section{Discussion}

Consistent with previous clinical and experimental data (5-13), we found that diabetes delayed fracture healing in a rat model of closed fracture. This delay was initiated at early stages of healing, demonstrated by the development of abundant soft tissue formation (almost two times greater in diabetic rats than in controls) and a significant deficiency of chondrogenesis and osteogenesis in the fracture site of the diabetic group. As mechanical stability of the fracture callus was restored through endochondral and intramembranous ossification, we can assume that the initial impairment of chondrogenesis and osteogenesis observed in diabetic rats contributed to the low stability of the fracture site and inappropriate alignment of fragments of this group, as shown by radiographic analysis. Furthermore, the fracture callus in diabetes has decreased mechanical strength, which has been associated with changes in collagen expression $(6,20,21)$, chondrocyte maturation (21) and retarded mineralization (11-12). The disjointing of bone fragments enlarges the volume of the callus by increasing osteogenesis and chondrogenesis in the latter stages. Consequently, long time periods are required for remodeling and complete bone consolidation following delayed union, non-union, or pseudoarthrosis. Taken together, these

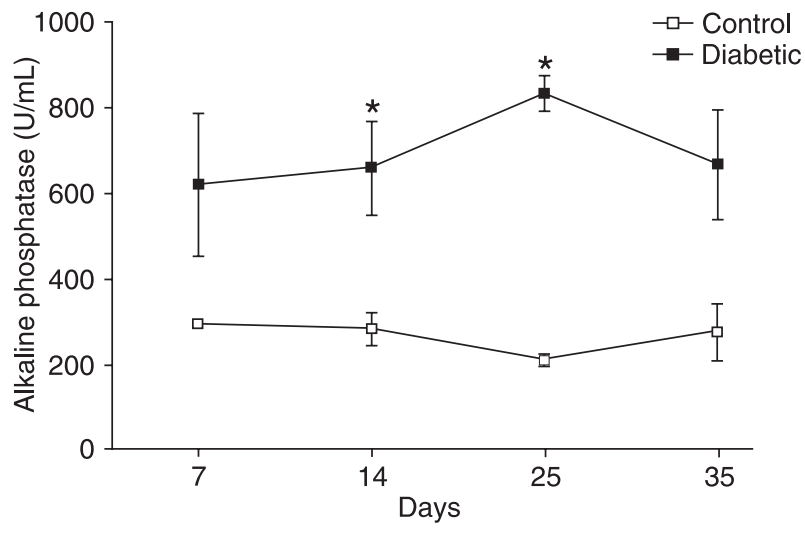

Figure 4. Serum alkaline phosphatase (ALP) of diabetic and control rats $7,14,25$, and 35 days after fracture. Serum concentration of ALP was measured colorimetrically as described in Material and Methods. Results are reported as means \pm SD in units ( $\mu \mathrm{mol}$ thymolphthalein released $/ \mathrm{min}$ ) per $\mathrm{mL}$. ${ }^{*} \mathrm{P}=0.009$ compared to respective control (Mann-Whitney test).

results suggest that formation of the bony callus in the diabetic group was delayed, but not inhibited. By days 14, 25 and 35, the area of cartilage and bone in the fracture callus was larger in diabetics than in controls. Persistence of a large cartilaginous callus, together with trabecular bone with sparse spacing, suggested delayed healing in diabetics and a less mature fracture callus in these animals.

Consistent with the increase of osteogenesis in the diabetic group, the serum levels of ALP, a marker of bone formation, were also significantly increased in this group. We also found a positive correlation between the levels of ALP in serum with bone formation in diabetic rats. These results may suggest that alloxan-induced diabetes affects the process of matrix formation and mineralization in the 
bone, as reported in other diabetes models (6-12,21-24).

The effects of alloxan-induced diabetes on bone tissue include decreased trabecular bone volume and cortical width, increased bone collagen glycosylation and decreased rate of bone resorption (30). We observed that alloxan-treated rats showed morphologic alterations in the pancreatic islets $(27,28)$. Controlled insulin therapy may revert the disorders in fracture repair observed in the poorly compensated diabetic metabolic state $(8,11,12,21)$; however, in the usual clinical situation, a diabetic patient with insulin-dependent type 1 diabetes treated with insulin may still suffer from an overall poor diabetic metabolic state with an uncontrollable or hardly controllable bloodglucose level and a high and sometimes changing insulin requirement. Thus, glycemic control in humans is pivotal for improving or increasing the speed of the healing process after injury and decreasing the significant morbidity associated with uncontrollable blood-glucose levels dur-

\section{References}

1. Dib SA, Russo EMK, Chacra AR. Tratado de endocrinologia clínica. São Paulo: Editora Rocca; 1992.

2. King $\mathrm{H}$, Rewers M. Global estimates for prevalence of diabetes mellitus and impaired glucose tolerance in adults. WHO Ad Hoc Diabetes Reporting Group. Diabetes Care 1993; 16: 157-177.

3. King $\mathrm{H}$, Aubert RE, Herman WH. Global burden of diabetes, 1995-2025: prevalence, numerical estimates, and projections. Diabetes Care 1998; 21: 1414-1431.

4. Malerbi DA, Franco LJ. Multicenter study of the prevalence of diabetes mellitus and impaired glucose tolerance in the urban Brazilian population aged 30-69 yr. The Brazilian Cooperative Group on the Study of Diabetes Prevalence. Diabetes Care 1992; 15: 1509-1516.

5. Loder RT. The influence of diabetes mellitus on the healing of closed fractures. Clin Orthop Relat Res 1988; 210-216.

6. Macey LR, Kana SM, Jingushi S, Terek RM, Borretos J, Bolander ME. Defects of early fracture-healing in experimental diabetes. J Bone Joint Surg Am 1989; 71: 722-733.

7. Funk JR, Hale JE, Carmines D, Gooch HL, Hurwitz SR. Biomechanical evaluation of early fracture healing in normal and diabetic rats. J Orthop Res 2000; 18: 126-132.

8. Beam HA, Parsons JR, Lin SS. The effects of blood glucose control upon fracture healing in the BB Wistar rat with diabetes mellitus. J Orthop Res 2002; 20: 1210-1216.

9. Follak N, Kloting I, Ganzer D, Merk H. Scanning electron microscopic examinations on retarded bone defect healing in spontaneously diabetic $\mathrm{BB} / \mathrm{O}$ (ttawa) $\mathrm{K}$ (arlsburg) rats. Histol Histopathol 2003; 18: 111-120.

10. Follak N, Kloting I, Wolf E, Merk H. Histomorphometric evaluation of the influence of the diabetic metabolic state on bone defect healing depending on the defect size in spontaneously diabetic BB/OK rats. Bone 2004; 35: 144-152.

11. Follak N, Kloting L, Wolf E, Merk H. Delayed remodeling in ing fracture healing.

The present study, to our knowledge, represents the first histomorphometric analysis of the effect of alloxaninduced diabetes on bone fracture healing. Our findings suggest that the diabetic state induced by alloxan delays chondrogenesis and osteogenesis in the first stages of fracture healing. As a consequence, there is inappropriate stability of fractured fragments, which contributes to the increase in the volume of callus in later stages and requires long periods of time for remodeling and complete bone consolidation.

\section{Acknowledgments}

The authors are grateful to Gabriela Mariângela Farias de Oliveira, Édelyn Cristina Nunes Silva and Renata Ribeiro de Souza from the University of Brasília for their helpful technical assistance. the early period of fracture healing in spontaneously diabetic $\mathrm{BB} / \mathrm{OK}$ rats depending on the diabetic metabolic state. Histol Histopathol 2004; 19: 473-486.

12. Follak N, Kloting I, Merk $\mathrm{H}$. Influence of diabetic metabolic state on fracture healing in spontaneously diabetic rats. Diabetes Metab Res Rev 2005; 21: 288-296.

13. Vestergaard $P$. Discrepancies in bone mineral density and fracture risk in patients with type 1 and type 2 diabetes - a meta-analysis. Osteoporos Int 2007; 18: 427-444.

14. Udupa KN, Prasad GC. Chemical and histochemical studies on the organic constituents in fracture repair in rats. $J$ Bone Joint Surg Br 1963; 45: 770-779.

15. Bolander ME. Regulation of fracture repair by growth factors. Proc Soc Exp Biol Med 1992; 200: 165-170.

16. Einhorn TA. Enhancement of fracture-healing. $J$ Bone Joint Surg Am 1995; 77: 940-956.

17. Einhorn TA, Majeska RJ, Rush EB, Levine PM, Horowitz MC. The expression of cytokine activity by fracture callus. $J$ Bone Miner Res 1995; 10: 1272-1281.

18. Salvi GE, Yalda B, Collins JG, Jones BH, Smith FW, Arnold $\mathrm{RR}$, et al. Inflammatory mediator response as a potential risk marker for periodontal diseases in insulin-dependent diabetes mellitus patients. J Periodontol 1997; 68: 127-135.

19. Wetzler C, Kampfer H, Stallmeyer B, Pfeilschifter J, Frank $\mathrm{S}$. Large and sustained induction of chemokines during impaired wound healing in the genetically diabetic mouse: prolonged persistence of neutrophils and macrophages during the late phase of repair. J Invest Dermatol 2000; 115: 245-253.

20. Topping RE, Bolander ME, Balian G. Type $X$ collagen in fracture callus and the effects of experimental diabetes. Clin Orthop Relat Res 1994; 220-228.

21. Gooch HL, Hale JE, Fujioka H, Balian G, Hurwitz SR. Alterations of cartilage and collagen expression during fracture 
healing in experimental diabetes. Connect Tissue Res 2000; 41: 81-91.

22. Weiss RE, Reddi $A H$. Influence of experimental diabetes and insulin on matrix-induced cartilage and bone differentiation. Am J Physiol 1980; 238: E200-E207.

23. He H, Liu R, Desta T, Leone C, Gerstenfeld LC, Graves DT. Diabetes causes decreased osteoclastogenesis, reduced bone formation, and enhanced apoptosis of osteoblastic cells in bacteria stimulated bone loss. Endocrinology 2004; 145: 447-452.

24. Suzuki K, Kurose T, Takizawa M, Maruyama M, Ushikawa $\mathrm{K}$, Kikuyama M, et al. Osteoclastic function is accelerated in male patients with type 2 diabetes mellitus: the preventive role of osteoclastogenesis inhibitory factor/osteoprotegerin (OCIF/OPG) on the decrease of bone mineral density. Diabetes Res Clin Pract 2005; 68: 117-125.

25. Neumann A, Schinzel R, Palm D, Riederer P, Munch G. High molecular weight hyaluronic acid inhibits advanced glycation endproduct-induced NF-kappaB activation and cytokine expression. FEBS Lett 1999; 453: 283-287.

26. Goova MT, Li J, Kislinger T, Qu W, Lu Y, Bucciarelli LG, et al. Blockade of receptor for advanced glycation end-products restores effective wound healing in diabetic mice. Am J Pathol 2001; 159: 513-525.

27. Katsumata K, Katsumata K Jr, Katsumata Y. Protective effect of diltiazem hydrochloride on the occurrence of alloxan- or streptozotocin-induced diabetes in rats. Horm Metab Res 1992; 24: 508-510.

28. Szkudelski T. The mechanism of alloxan and streptozotocin action in B cells of the rat pancreas. Physiol Res 2001; 50: 537-546.

29. An YH, Friedman RJ. Animal models in orthopedic research. Boca Raton: CRC Press; 1999.

30. Locatto ME, Abranzon H, Caferra D, Fernandez MC, Alloatti R, Puche RC. Growth and development of bone mass in untreated alloxan diabetic rats. Effects of collagen glycosylation and parathyroid activity on bone turnover. Bone Miner 1993; 23: 129-144. 